\title{
Gene-Environment Interaction in Adults' IQ Scores: Measures of Past and Present Environment
}

\author{
Sophie van der Sluis · Gonneke Willemsen • \\ Eco J. C. de Geus · Dorret I. Boomsma • \\ Danielle Posthuma
}

Received: 25 January 2008/ Accepted: 22 May 2008/Published online: 6 June 2008

(C) The Author(s) 2008

\begin{abstract}
Gene-environment interaction was studied in a sample of young (mean age 26 years, $N=385$ ) and older (mean age 49 years, $N=370$ ) adult males and females. Full scale IQ scores (FSIQ) were analyzed using biometric models in which additive genetic (A), common environmental (C), and unique environmental (E) effects were allowed to depend on environmental measures. Moderators under study were parental and partner educational level, as well as urbanization level and mean real estate price of the participants' residential area. Mean effects were observed for parental education, partner education and urbanization level. On average, FSIQ scores were roughly 5 points higher in participants with highly educated parents, compared to participants whose parents were less well educated. In older participants, IQ scores were about 2 points higher when their partners were highly educated. In younger males, higher urbanization levels were associated with slightly higher FSIQ scores. Our analyses also showed increased common environmental variation in older males whose parents were more highly educated, and increased unique environmental effects in older males living in more affluent areas. Contrary to studies in children, however, the variance attributable to additive genetic effects was stable
\end{abstract}

Edited by Stacey Cherny.

S. van der Sluis $(\bowtie) \cdot$ G. Willemsen · E. J. C. de Geus .

D. I. Boomsma · D. Posthuma

Department of Biological Psychology, VU University

Amsterdam, Van der Boechorststraat 1, Amsterdam 1081 BT,

The Netherlands

e-mail: s.van.der.sluis@psy.vu.nl

D. Posthuma

Department of Clinical Genetics, Section Medical Genomics,

VU Medical Centre, van der Boechorststraat 7,

Amsterdam 1081 BT, The Netherlands across all levels of the moderators under study. Most results were replicated for VIQ and PIQ.

Keywords $\mathrm{G} \times \mathrm{E}$ interaction $\cdot \mathrm{IQ} \cdot \mathrm{SES}$. Parental education · Partner education - Urbanization . Mean real estate price

\section{Introduction}

Heritability of cognitive ability is at present no longer in dispute: many behavior genetics studies have shown that additive genetic influences (A) explain large parts of the observed variation in cognitive functioning in both children and adults (e.g., Bouchard and McGue 1981; McCartney et al. 1990; Bratko 1996; Devlin et al. 1997; Rijsdijk et al. 2002; Alarcón et al. 1998; Posthuma et al. 2000), and that these influences tend to increase with age, while shared environmental influences (C) decrease (e.g., Bartels et al. 2002; McCartney et al. 1990; McGue et al. 1993; Plomin et al. 1997; Boomsma et al. 2002; Polderman et al. 2006; Bergen et al. 2007).

The broad range heritability estimates $\left(\mathrm{h}^{2}\right)$ reported in these studies vary roughly between $26 \%$ and $85 \%$, and concern sample-based estimates, the assumption being that the heritability is equal for different subgroups and stable across environmental conditions. Several studies however suggest that in children, the heritability estimates for cognitive ability depend on characteristics of the childhood home-environment such as parental income (Harden et al. 2007), parental socioeconomic status (SES, Turkheimer et al. 2003), parental educational level (Rowe et al. 1999), quality of parent-child communication and degree of chaos in the home-environment (Asbury et al. 2005). These interactions between measured environmental variables and 
unmeasured (i.e., latent) genetic influences, often referred to as $\mathrm{G} \times \mathrm{E}$, are not always replicated (e.g., Nagoshi and Johnson 2005; van den Oord and Rowe 1997), and neither is the 'direction' of the interaction consistent across studies. Moreover, most studies on $\mathrm{G} \times \mathrm{E}$ interaction in cognitive ability have been conducted in samples of children or adolescents (age 17 or below), while studies conducted in adult samples are sparse. The aim of the current study is to investigate whether characteristics of the childhood homeenvironment influence heritability estimates of cognitive ability in adulthood. In addition, we investigate whether characteristics of the present, adulthood, living environment moderate the heritability of cognitive ability in adults.

Some $\mathrm{G} \times \mathrm{E}$ results observed in children support the diathesis-stress model (Gottesman 1991; Paris 1999). The diathesis-stress model is based on the assumption that sensitivity to environmental risk factors is larger in individuals who are at genetic risk for a disorder, compared to those who are not at genetic risk (e.g., Plomin and Rutter 1998). The diathesis-stress model predicts genetic influences to be larger in less advantageous environmental circumstances. Support for this model in the context of cognitive ability, was reported by Asbury et al. (2005), who studied variation in genetic influences on verbal and nonverbal ability as a function of 10 environmental variables in 4-year-old same-sex twins. For verbal ability, interactions involving measures of family chaos, and instructive and informal parent-child communication proved significant, with heritability being higher in less favourable circumstances. Interactions with SES, maternal depression, harsh parenting, and negative parental feelings however were not significant, and no interactions were observed for nonverbal ability.

The alternative so-called bio-ecological model formulated by Bronfenbrenner and Ceci (1994), predicts that genetic potential will be actualized to a larger degree when so-called 'proximal processes' are strong. Here, proximal processes are defined as those processes that enhance effective developmental functioning. When proximal processes are strong, environmental differences in developmental outcome are reduced, and the individual differences induced by genetic effects increase (Bronfenbrenner and Ceci 1994, pp. 572-574). Following this model, heritability is largest in advantageous, stable environments. In line with this model, Turkheimer et al. (2003) reported increased heritability of WISC-scores in 7-yearold children from more affluent families. More specifically, in children from a high SES-group (with SES defined as a linear combination of parental income, education and occupational status), the proportion of variance attributable to genetic influences was larger and shared environmental effects smaller $\left(\mathrm{h}^{2}=0.72, \mathrm{c}^{2}=0.15\right)$, compared to a low SES-group $\left(\mathrm{h}^{2}=0.10, \mathrm{c}^{2}=0.58\right)$. In this study, the large common environmental effect $\left(c^{2}\right)$ reported for the low
SES group, which included a high percentage of impoverished families, is somewhat surprising as one would not expect much variation in familial circumstances in this group. A similar, albeit weaker, interaction was reported by Harden et al. (2007) for 17-year-old children. They observed higher heritability for general cognitive ability, and smaller shared environmental effects in children from higher income families $\left(\mathrm{h}^{2}=0.55, \mathrm{c}^{2}=0.35\right)$, compared to children from families with lower income $\left(\mathrm{h}^{2}=0.39\right.$, $\left.\mathrm{c}^{2}=0.45\right)$. With respect to the moderation effect of parental educational attainment level, Rowe et al. (1999) reported higher heritability of vocabulary level in 16-yearold children from more highly educated families $\left(\mathrm{h}^{2}=0.74, \mathrm{c}^{2}=0.00\right)$, than in children from less welleducated families $\left(\mathrm{h}^{2}=0.26, \mathrm{c}^{2}=0.23\right)$. This interaction with parental educational attainment was replicated by Kremen et al. (2005) in a sample of adult males (mean age about 40 years), where heritability of word recognition ability was found to be higher in males from higher educated families $\left(\mathrm{h}^{2}=0.69, \mathrm{c}^{2}=0.00\right)$, compared to males from less well-educated families $\left(\mathrm{h}^{2}=0.21, \mathrm{c}^{2}=0.52\right)$.

Because many 'environmental' moderators may themselves be under genetic influence (e.g., Plomin et al. 2001), the possibility exists that the environmental moderator under study and the trait under study have additive genetic influences in common. In that case, the moderator is correlated to the genetic effects of the trait ( $\mathrm{rGE}$ ) rather than modifying the genetic effects of the trait $(\mathrm{G} \times \mathrm{E}$, Purcell 2002). Since $\mathrm{rGE}$ can appear as $\mathrm{G} \times \mathrm{E}$ in statistical analyses, one should either model rGE explicitly, or correct for the presence of rGE by including moderator effects on the mean of the trait in the model (Purcell 2002). Several of the studies which report significant $\mathrm{G} \times \mathrm{E}$ results explicitly accounted for the possible presence of rGE by including moderator effects on the mean of the trait (Kremen et al. 2005; Turkheimer et al. 2003; Harden et al. 2007), ensuring that the reported $\mathrm{G} \times \mathrm{E}$ effects are not artefacts of $\mathrm{rGE}$.

At present, the study by Kremen et al. (2005) is the only study on $\mathrm{G} \times \mathrm{E}$ interaction in adulthood cognitive ability. In this adult male sample, the higher heritability of the specific skill of 'word recognition' in subjects whose parents were highly educated, was due to a decrease in shared environmental effects, rather than an absolute increase in the effects of genetic factors. Yet, this study illustrates that variables like parental educational attainment level, which characterizes the childhood home-environment, may have long-lasting effects on the variance decomposition of word recognition ability. The exact nature of these long-lasting effects is yet unknown, but possibly parental educational attainment level influences the variance decomposition of word recognition ability in childhood, which then remains stable over time. Alternatively, parental educational attainment level could also be a proxy of one's own 
adulthood educational attainment level, as such indirectly moderating the variance decomposition of cognitive ability in adulthood. Other mechanisms are still conceivable. Irrespective of the exact nature of the moderating mechanism, the present study set out to test whether similar moderation effects of parental educational attainment level can be detected for adulthood psychometric IQ scores, as has been observed for childhood IQ.

As noted earlier, the environmental moderators studied thus far all concern characteristics of the childhood homeenvironment that were not under the control of the subjects under investigation. That is, variables like parental education and income, and the extent of informal/instructive parent-child communication or chaos in the home, typify familial circumstances that are in essence largely 'imposed', and not determined by the children whose cognitive ability was under study. In adulthood however, environmental conditions are at least partly self-selected. Such self-selected circumstances could also moderate the extent to which genetic and environmental factors influence the individual differences observed in psychometric IQ-scores. In the present paper, we therefore also studied the moderating effects of three adulthood environmental characteristics that are at least partly self-selected and form an indication of the participants present living conditions: the educational attainment of the participants' partners, mean real estate price of the participants residential area, and, more exploratory, urbanization level of the participants residential area.

Partner educational attainment level was chosen as moderator to test whether, in line with the moderating results described for parental educational attainment level (Kremen et al. 2005; Rowe et al. 1999), the variance decomposition of psychometric IQ scores depends on the educational attainment level of one's partner. Just like with parental educational attainment level, higher partner educational attainment level could be associated with higher heritability. Assuming that more highly educated partners constitute an intellectually more stimulating environment, this hypothesis is in line with the bio-ecological model, which predicts that genetic potential is actualized to a larger degree under more favorable circumstances. As partner choice is not random, and assortative mating with respect to cognitive ability is likely to take place (e.g., Reynolds et al. 2000), effects of partner educational attainment level should be modeled on both the means and the variances. Mean real estate price can be regarded as a rough measure of current income. This variable was chosen as moderator to test whether, in line with the reported moderating effects of parental income and SES (Harden et al. 2007; Turkheimer et al. 2003), genetic influences on IQ are higher under more favorable socioeconomic circumstances. Several studies have shown that high urbanization levels are associated with decreased mental and physical health, for instance higher rates of cardiovascular disease, schizophrenia, and depression (e.g., Pedersen and Mortensen 2001; Peen and Dekker 2003; Sundquist and Frank 2004; Sundquist et al. 2004a, b; Willemsen et al. 2005). Possible causes are reduced community support, selective migration, increased access to stimulants (drugs, alcohol), and increased social stress due to high population density. These factors may directly, or indirectly through mental en physical health effects, reduce the extent to which an individuals' genetic potential is expressed. At the same time, the extent of intellectual stimulation may be higher in more highly urbanized areas, which may help to maximize genetic potential.

In sum, the present study focuses on uncovering the possible moderating effects of parental educational level, partner educational level, mean real estate price and urbanization level on the variability observed in adulthood IQ scores.

\section{Method}

\section{Subjects}

Subjects were registered at the Netherlands Twin Registry (Boomsma et al. 2006) and participated in an ongoing project on the genetics of cognition. Data were available for 314 extended twin families: 58 monozygotic male pairs, 72 monozygotic female pairs, 33 dizygotic male pairs, 63 dizygotic female pairs, 48 dizygotic opposite sex pairs, and their siblings. The total group consisting of 755 subjects (329 males and 427 females). Zygosity was determined based on information from questionnaires, blood group, and typing of highly polymorphic markers.

The distribution of age was clearly bimodal, with a cut around age 36 (see Posthuma et al. 2001 for a more detailed description of this sample). Following Posthuma et al., the sample was therefore split up in two age-cohorts: a young cohort (under 36 years of age, minimum age 20 years, $N=385$ ) with a mean age of 26.56 years $(\mathrm{SD}=3.76)$, and an older cohort (36 years and older, maximum age 69 years, $N=370$ ) with a mean age of 49.39 years $(\mathrm{SD}=6.99)$. To preserve family structure, allocation of the siblings of twins to one of the two cohorts, was based on the age of the twins, which resulted in a slight overlap in age between the cohorts ( 8 siblings older than 36 years were allocated to the young cohort, 2 siblings younger than 36 were allocated to the older cohort). It is possible that the moderator effects on psychometric IQ differ between the two age-cohorts. For example, heritability may change due to age-related changes in geneexpression (Bergen et al. 2007), and the proportion of variance due to unique environmental factors may increase 
with age, simply because family members no longer share the same household. Considering the bimodality of the age distribution, a categorical moderator (i.e., cohort) was deemed more appropriate than a continuous moderator (actual age), because of the small number of observations in some of the intermediate age levels.

Likewise, following the idea that opportunities and expectations with respect to education and career may be different for males and females, it is conceivable that moderator effects differed across sex. Sex and cohort status were therefore included in all subsequent analyses.

\section{Instruments}

Psychometric IQ was measured with an abridged version of the Dutch WAIS-III (WAIS-III 1997). Full scale IQ-scores (FSIQ) were based on the following nine subtests: Information (IF), Similarities (SIM), Vocabulary (VOC), Arithmetic (AR), Letter-Number Sequencing (LN), Block Design (BP), Matrix Reasoning (MX), Picture Completion (PC) and Symbol Substitution (SYM). FSIQ-scores were corrected for age- and sex-effects prior to the analyses.

The educational attainment level of partners and parents was determined through questionnaires in which participants reported their own educational level. If self reports of parents and partners were missing, twin and sibling reports of their parents/partners educational level were used. If participants within a family did not agree on the level of educational attainment of their parents, the variable was coded as missing. Mid-parent educational attainment was calculated as the average between reported paternal and maternal education. Initially, four educational categories were distinguished (following e.g., Stronks et al. 1997; Schrijvers et al. 1999): primary education only (1), lower general and vocational education (2), intermediate vocational education, and intermediate/higher general education (3), and higher vocational education, college and university (4). Some levels however, showed very low endorsement: very few partners of participants from the younger cohort endorsed level 1 (only primary education: 2 partners of male, and 5 partners of female participants, respectively), and very few mothers of participants from the older cohort endorsed level 4 (higher vocational education, college and university: 4 mothers of male participants, and 4 mothers of female participants, respectively). For reasons of power and coverage, we therefore decided to collapse educational levels 1 and 2, and educational levels 3 and 4, such that partner education and mid-parent education were coded as lower (0) or higher (1) educational attainment level (for more details, see results section). Note that parental educational attainment is measured at family-level, and thus necessarily equal for all twins and siblings within a family.
Urbanization level of the participant's residential area, and mean real estate prices in the participant's residential area, were determined by linking the participants postal codes to the 1992 postal code information provided by Statistics Netherlands (Centraal Bureau voor de Statistiek 2001). Statistics Netherlands manages a public national data base that covers a wide variety of societal and economical aspects of the Dutch society. For each postal code, Statistic Netherlands provides an urbanization level (scale of 0-4: very high, high, moderate, low, very low/none), and an indication of the mean price of the real estate in that postal area. Mean real estate price was standardized (z-scores) before entering it as a moderator in subsequent analyses.

\section{Statistical analyses}

A series of interaction models was fitted for each moderator separately. Moderator effects on the means were included to allow for possible main effects of the moderator on the mean of the dependent variable (FSIQ), and to adjust for possible gene-environment correlation (rGE, Purcell 2002). In the context of the $\mathrm{G} \times \mathrm{E}$ twin-model proposed by Purcell, one form of rGE can be modeled explicitly in a bivariate Cholesky decomposition. Such a bivariate model requires variation in both the moderator and IQ between members of the same family. As parental educational attainment is a family-level variable, which shows no variation between twins and siblings from the same family, explicit modeling of rGE was not possible for this moderator. Explicit modeling of rGE was in principal possible for urbanization level, mean real estate price and partner educational level. However, the correlations between these moderators and FSIQ turned out to be low to such an extent (see Table 1) that explicit modeling of these correlations was deemed redundant. Note that inclusion of moderator effects on the means in essence implies partialling out the effect of the moderator, i.e., the variance shared with the moderator is accounted for, after which the remaining (residual) variance is decomposed into additive genetic influences (A), shared environmental influences $(\mathrm{C})$, and unshared environmental influences $(\mathrm{E})$. These latter three variance components, in turn, were allowed to vary depending on the level of the environmental moderator.

The full model is illustrated in Fig. 1 for a twin pair without siblings. When available, sibling data were however included in all analyses. MZ twin pairs reared together share $100 \%$ of their familial environment and $100 \%$ of their genes, so correlations between these variance components are fixed to $1 . \mathrm{DZ}$ twins and regular sib pairs reared together share $100 \%$ of their familial environmental and $50 \%$ of their genes on average, so correlations between these components are fixed to 1 and 0.5 , respectively 


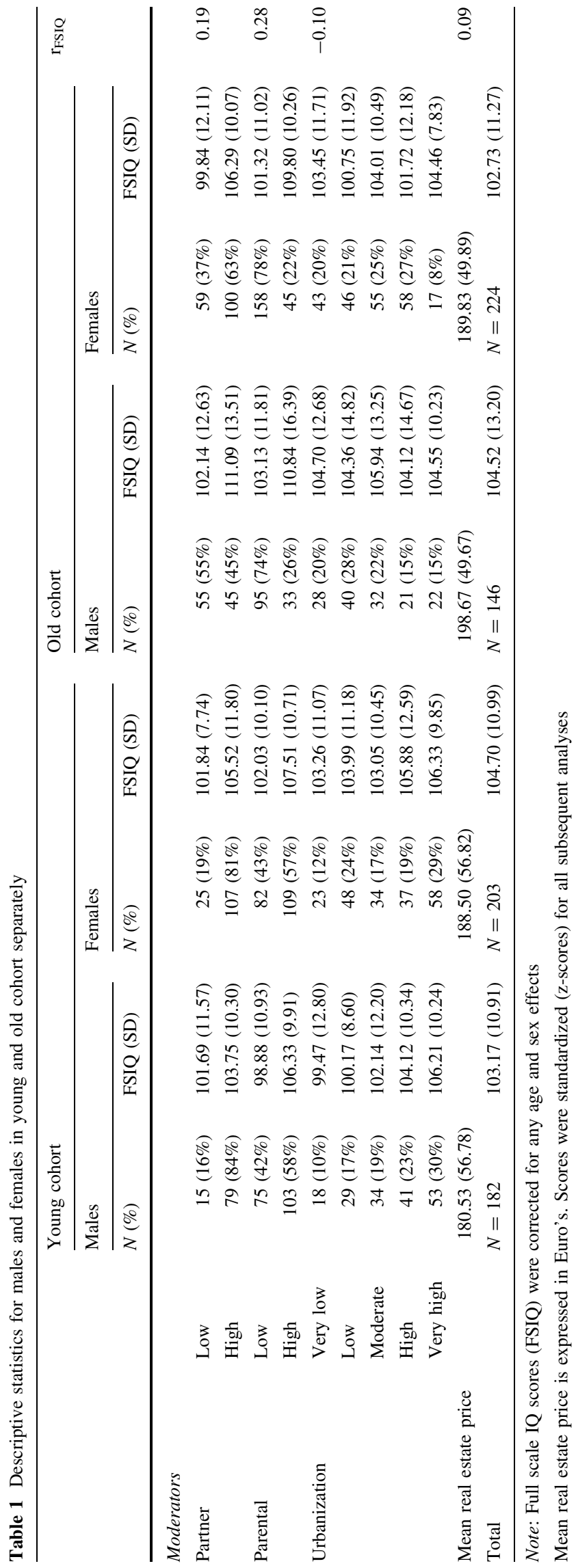

(Posthuma et al. 2003). In Fig. 1, the moderator is denoted as $\operatorname{Mod}_{\mathrm{tw} 1}$ or $\operatorname{Mod}_{\mathrm{tw} 2}$ for twin 1 and twin 2, respectively. The model includes 2 parameters for the means: an intercept $(\mathrm{m})$, which is independent of the moderator, and a slope $\left(\mathrm{m}^{\prime}\right)$, which is dependent on the moderator. For the variances, the full model included 6 parameters: the parts of $\mathrm{A}, \mathrm{C}$ and $\mathrm{E}$ that are independent of the moderator (denoted a, c, and e), and the parts of $\mathrm{A}, \mathrm{C}$ and $\mathrm{E}$ that depend on the moderator (denoted $\mathrm{a}^{\prime}, \mathrm{c}^{\prime}$, and $\mathrm{e}^{\prime}$ ). To begin with, all 8 parameters were estimated separately for males and females, and for the young and the older cohort (i.e., 32 parameters in total), which allowed us to study $\mathrm{G} \times \mathrm{E}$ interaction separately for young/older males/females.

Note that educational attainment was coded as 0 (lower educational attainment), and 1 (higher educational attainment). This coding implies that a 'baseline' model is estimated for the low educational attainment groups, while the deviations from this model for the higher educational attainment group are modeled through the moderation parameters $\left(\mathrm{m}^{\prime}, \mathrm{a}^{\prime}, \mathrm{c}^{\prime}\right.$, and $\left.\mathrm{e}^{\prime}\right)$. Similarly, urbanization level was coded $0,1,2,3,4$, implying the estimation of a 'baseline' model for the group living in a very highly urbanized region (0), and linear deviations thereof for the groups living in less urbanized areas.

With the full model in place, we fitted a series of nested (more restricted) models in which we constrained parameters to be equal across groups (to test for sex and/or cohort effects), or fixed parameters to zero to test for their significance. The fit of nested models was compared to the fit of less-restricted models through likelihood-ratio tests. The difference in -2 times the log-likelihoods of the competing models is asymptotically distributed as a chi-square $\left(\chi^{2}\right)$, with df equal to the difference in the number of parameters estimated (the degrees of freedom are reported in parentheses with the $\chi^{2}$ ). All effects were tested against a criterion level $\alpha$ of 0.05 .

\section{Results}

Preliminary analyses

Descriptive statistics are presented in Table 1, separately for males and females in the young and older cohort. As mentioned, the FSIQ scores were corrected for possible sex and age-effects, so the IQ scores did not differ significantly between the four groups $(F(3,751)=1.40, n s)$.

With respect to the moderator variables, Kruskal-Wallis tests showed that the four groups (by sex and cohort) differed with respect to the reported educational attainment of partners $\left(\chi^{2}(3)=47.77, P<0.001\right)$, and parents $\left(\chi^{2}(3)=82.90, P<0.001\right)$. These differences were due to generational differences: within cohorts, educational 


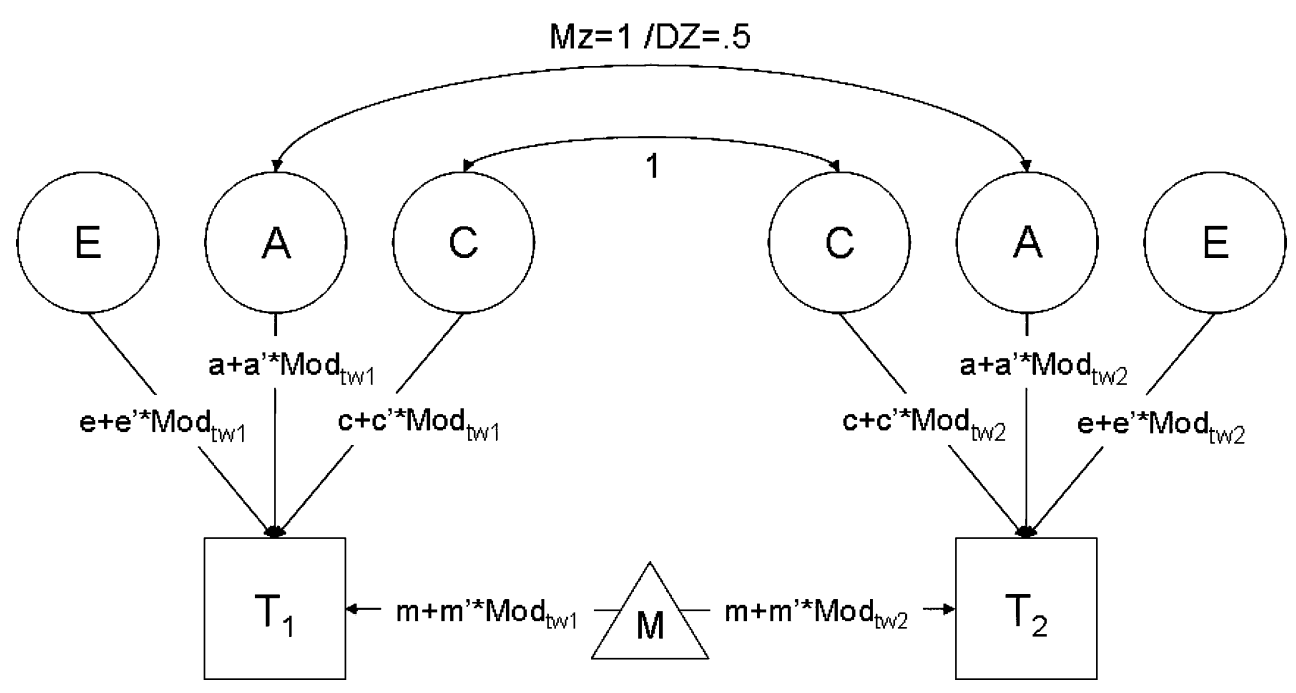

Fig. 1 Path diagram of the biometric model including moderation effects of the observed environmental moderator on the variances and the mean of the twin 1 and twin 2. Parameters a, c and e denote the parts of variance components A (additive genetic effects), C (common environmental effects) and $\mathrm{E}$ unique environmental effects) that are unrelated to the moderator, while a', c', and e' denote the parts of A, $\mathrm{C}$ and $\mathrm{E}$ that depend on the moderator (i.e., the interaction terms). For the mean, parameter $m$ denotes the intercept which is independent of the moderator, and m' denotes the slope, which is dependent on the moderator attainment levels of partners and parents were equal across male and female participants $\left(\chi^{2}(1)=2.79, n s\right.$, and $\chi^{2}(1)=2.04, n s$, respectively).

The four groups also differed with respect to urbanization level $\left(\chi^{2}(3)=34.13, P<0.001\right)$, with younger participants living in more highly urbanized areas than older participants. Within cohorts, no sex differences were observed (young cohort: $\chi^{2}(1)=1.36$, $n s$, older cohort: $\left.\chi^{2}(1)<1, n s\right)$.

Finally, group differences were observed for mean real estate price in the area where the participants lived $(F(3,732)=3.11, P<0.05)$. More specifically, post hoc Tukey HSD tests showed that young males more often lived in areas with lower mean real estate prices than the older males $(P=0.01)$, while none of the other group differences were statistically significant.

Note that these sex- and cohort-differences with respect to the mean (or mean-rank) of the moderator variables do not necessarily imply that these moderators will also show different moderation effects on the means and variances of FSIQ across the groups. Yet, allowing for sex and cohort effects in the following $\mathrm{G} \times \mathrm{E}$ interaction models does seem prudent.

Missing value analyses showed that subjects with and without missing values for urbanization level and mean real estate price did not differ with respect to their FSIQ scores (for both, $F(1,753)<1, n s$ ). Across the entire sample, however, subjects whose partner or parental educational level was unknown, had significantly lower FSIQ scores than subjects with known partner or parental educational level (partner educational level: $F(1,753)=6.26$,
$P=0.01$, FSIQ for subjects with missing partner data: $\mathrm{M}=102.34$ (SD = 11.16), FSIQ for subjects with known partner data: $\mathrm{M}=104.53$ ( $\mathrm{SD}=11.66)$; parental educational level: $F(1,752)=8.23, P<0.01$, FSIQ for subjects with missing parental data: $\mathrm{M}=99.47(\mathrm{SD}=10.28$ ), FSIQ for subjects with known parental data: $\mathrm{M}=104.08$ $(\mathrm{SD}=11.56)$. Because parental education was a familylevel moderator (i.e., observations within families cannot be considered independent), and because FSIQ scores of subjects from the same family can also not be considered independent, we also performed missing values analyses for the first subjects of each family only. The difference in FSIQ scores between subjects with and without information for partner and parental educational attainment decreased noticeably (partner educational level: $F(1,292)=3.60, P=0.06$; parental educational level: $F(1,292)=4.67, P<0.05)$ but remained considerable.

\section{$\mathrm{G} \times \mathrm{E}$ interaction models}

Before testing for $\mathrm{G} \times \mathrm{E}$ interaction in FSIQ, we fitted a model with only FSIQ for young and older males and females separately (i.e., four-group analysis without moderating effects, for this model: $-2 \operatorname{LL}(739)=5601.84)$. In this model, the variance components for A and E could be equated across the four groups, and the variance component corresponding to shared environment $(\mathrm{C})$ could be dropped from the model $\left(\chi^{2}(10)=15.28, n s\right)$. That is, in these participants, the variance in FSIQ was explained by additive genetic effects $\left(\mathrm{A}, \mathrm{h}^{2}=0.82\right)$, and unshared environmental effects $\left(E, \mathrm{e}^{2}=0.18\right)$, while shared 
environmental effects (C) did not explain any variance. The finding that shared environmental effects no longer explain a significant proportion of the individual differences observed in FSIQ in adult subjects, is in agreement with many previous studies (e.g., Rijsdijk et al. 2002; Posthuma et al. 2001; Luciano et al. 2001; Wright et al. 2001). As expected, intercepts could also be set equal across the four groups $\left(\chi^{2}(3)=4.83, n s\right)$.

Tables 2-5 include fit information for all four moderator-models. As a start, it is informative to compare the fit of the full moderation-models (Model 1 in Tables 2-5) to the fit of the full model for FSIQ without moderation (a $16 \mathrm{df}-$ test in this case, as the full moderation-models include 12 additional parameters for moderation effects on the variance of FSIQ, and 4 additional parameters for moderation effects on the mean of FSIQ). If the difference in fit is not significant, then the moderator is unlikely to add much information (with such an omnibus test, it is of course possible that 1 or 2 of the 16 parameters are significant). If however the difference is significant, then the moderator is likely to have a significant effect on the mean and/or the variance of FSIQ. The fit of the full moderation models for partner educational attainment, urbanization level and mean real estate price did not differ significantly from the fit of the model for FSIQ without moderation $\left(\chi^{2}(16)=\right.$ $23.06, n s ; \chi^{2}(16)=8.61, n s ; \chi^{2}(16)=13.67, n s$, respectively), implying that moderation effects for these moderators are small or absent. For parental educational attainment, however, the difference in fit was highly significant $\left(\chi^{2}(16)=50.64, P<0.001\right)$, suggesting the presence of some sort of moderation. The exact relation between FSIQ and the moderators is investigated in more detail below.

In line with the findings for the unmoderated FSIQ model, the unmoderated parts of the variance components (parameters a, c and e) could be equated across sex and cohort (in all moderator models: Model 1a vs Model 1: $\left.\chi^{2}(9)<14.59, n s\right)$. The intercepts, i.e., the unmoderated part of the means model, could also be equated across sex and cohort (in all moderator models: Model $1 \mathrm{~b}$ vs Model 1a: $\left.\chi^{2}(3)<6.08, n s\right)$, and shared environment effects could be dropped from the model (in all moderator models: Model 1c vs Model 1b: $\left.\chi^{2}(1)<1.10, n s\right)$. Note that moderator effects modeled on the shared environment variance component $\mathrm{C}$ (i.e., parameter $\mathrm{c}^{\prime}$ ) remain in the model, i.e., shared environmental effects can still turn out to be significant for some levels of the moderators under study.

The constraints imposed in models 1a through 1c were deemed expedient because constraining the unmoderated part of the model, and dropping non-significant parameters from the model, increases the power to detect moderation effects. It should be noted, however, that the effects reported below, would decrease somewhat in size, but would not disappear entirely, when these constraints were not imposed.

Also, with a view to enhancing statistical power, our model fitting strategy included equating moderation parameters across sex and cohort first (if possible), before testing their significance.

For all moderators, the equated AE-model with intercepts constrained to be equal across sex and cohort, was therefore taken as point of departure (i.e., Model $1 \mathrm{c}$ in Tables 2-5).

\section{Parental educational attainment level}

First, the moderation effects of parental educational attainment (Table 2) on the variance components of FSIQ (i.e., parameters $\mathrm{a}^{\prime}, \mathrm{c}^{\prime}$ and $\mathrm{e}^{\prime}$ ) were constrained to be equal across sex and cohort (Model 2). This, however, resulted in a significant deterioration of the fit (Model 2 vs Model 1c: $\left.\chi^{2}(9)=18.00, P<0.05\right)$. The source of this misfit appeared to be the moderation in the group of older males: moderation effects in all other groups could be constrained to be equal (Model 2a vs Model 1c: $\chi^{2}(6)=2.77, n s$ ), and could subsequently be dropped from the model (Model $3 \mathrm{vs}$ Model 2a: $\left.\chi^{2}(3)<1, n s\right)$. To determine the exact source of the moderation for the older males, we fixed the three moderation parameters alternately to zero (for $\mathrm{a}^{\prime}{ }_{\text {om }}$ : Model 4a vs Model 3: $\chi^{2}(1)=2.27$, ns; for $\mathrm{c}^{\prime}{ }_{\text {om }}$ : Model $4 \mathrm{~b}$ vs Model 3: $\chi^{2}(1)=5.68, P<0.05$ : for $\mathrm{e}^{\prime}{ }_{\text {om }}$ : Model $4 \mathrm{c}$ vs Model 3: $\left.\chi^{2}(1)=1.63, n s\right)$. The only significant drop in fit was observed when the moderation on the shared environmental variance component, parameter $\mathrm{c}^{\prime}{ }_{\text {om }}$, was fixed to zero. That is, in contrast to the other groups, shared environmental effects accounted for some of the individual differences observed in older males from more highly educated families. Indeed, for older males, moderation of A and $\mathrm{E}$ could both be dropped from the model (Model 5 vs Model 3: $\left.\chi^{2}(2)=5.12, n s\right)$. Eventually, shared environmental effects explained $47 \%$ of the variance observed in older males from more highly educated families, while additive genetic effects and unshared environmental effects explained $42 \%$ and $11 \%$, respectively. In contrast, shared environmental effects did not explain any variance in older females, younger males and females, and older males from less educated families, while additive genetic effects and unshared environmental effects explained $80 \%$ and $20 \%$ of the variance, respectively.

Effects of parental education on the means could be equated across sex and cohort (Model 6 vs Model 7: $\left.\chi^{2}(3)=3.23, n s\right)$, and these effects were highly significant (Model 7 vs Model 6: $\chi^{2}(1)=31.50, P<0.001$ ). Specifically, FSIQ scores were on average 5 IQ points higher in children whose parents were more highly educated. 
Table 2 Model fitting results for an interaction model of full scale IQ with parental educational attainment level as moderator

\begin{tabular}{|c|c|c|c|c|c|c|}
\hline & Pareducr & $-2 \mathrm{LL}$ & Df & $\chi_{\text {diff }}^{2}$ & $\mathrm{Df}_{\text {diff }}$ & $P$ \\
\hline \multirow[t]{4}{*}{ Model } & Full model & 5551.197 & 723 & & & \\
\hline & $\begin{array}{l}\text { Equalize unmoderated parts of variance (a, c, an e) } \\
\text { across sex and cohort }\end{array}$ & 5561.361 & 732 & 10.164 & 9 & \\
\hline & Equalize unmoderated part means (m) across sex and cohort & 5567.441 & 735 & 6.08 & 3 & 0.11 \\
\hline & Drop parameter c & 5568.444 & 736 & 1.00 & 1 & \\
\hline Model 2 & $\begin{array}{l}\text { Equalize moderation parameters } \mathrm{a}^{\prime}, \mathrm{c}^{\prime} \text { and } \mathrm{e}^{\prime} \text { (variances) } \\
\text { across sex and cohort }\end{array}$ & 5586.443 & 745 & 17.999 & 9 & 0.035 \\
\hline $2 a$ & Equalize all but moderation for older males & 5571.212 & 742 & 2.77 & 6 & \\
\hline Model 3 & Drop all but moderation for older males & 5572.164 & 745 & $<1$ & 3 & \\
\hline Model 4a & Drop moderation A older males $\left(\mathrm{a}_{\mathrm{om}^{\prime}}\right)$ & 5574.436 & 746 & 2.72 & 1 & 0.10 \\
\hline $4 \mathrm{~b}$ & Drop moderation $\mathrm{C}$ older males $\left(\mathrm{c}_{\mathrm{om}^{\prime}}\right)$ & 5577.846 & 746 & 5.68 & 1 & 0.02 \\
\hline $4 c$ & Drop moderation $\mathrm{E}$ older males $\left(\mathrm{e}_{\mathrm{om}^{\prime}}\right)$ & 5573.793 & 746 & 1.63 & 1 & 0.20 \\
\hline Model 5 & Drop all but $\mathrm{c}_{\mathrm{om}^{\prime}}$ & 5577.279 & 747 & 5.12 & 2 & 0.08 \\
\hline Model 6 & Equalize moderation parameter means $\left(\mathrm{m}^{\prime}\right)$ across sex and cohort & 5580.511 & 750 & 3.23 & 3 & 0.36 \\
\hline Model 7 & Drop moderation means & 5612.013 & 751 & 31.50 & 1 & $<0.001$ \\
\hline \multicolumn{7}{|c|}{ Parameters final model } \\
\hline Means & $\begin{array}{l}\mathrm{m}=102.09 \\
\mathrm{~m}^{\prime}=5.09\end{array}$ & & Variances & $\begin{array}{l}\mathrm{A}=9.71 \\
\mathrm{E}=4.93 \\
\mathrm{C}_{\text {om }}^{\prime}=10.34\end{array}$ & & \\
\hline
\end{tabular}

Note: Parameters a, c and e refer to the unmoderated parts of the variance components A (additive genetic effects), C (common environmental effects) and $\mathrm{E}$ (unique environmental effects) of FSIQ, while parameters $\mathrm{a}^{\prime}, \mathrm{c}^{\prime}$ and $\mathrm{e}^{\prime}$ refer to the moderation parameters of these variance components. Parameter $\mathrm{m}$ refers to the unmoderated part of the means model, while parameter $\mathrm{m}^{\prime}$ refers to the moderation effect in the means. Subscripts refer to young (y) or old (o) and males (m) or females (f), respectively

\section{Partner's educational attainment level}

The moderation effects of partner's educational attainment level on the variance components of FSIQ (Table 3) could be constrained to be equal across sex and cohort (Model 2 vs Model 1c: $\left.\chi^{2}(9)=3.44, n s\right)$, and were not significantly different from zero (Model 3 vs Model 2: $\chi^{2}(3)=3.61$, $n s)$. In all groups, additive genetic effects accounted for
$82 \%$ of the variance observed in FSIQ, and unshared environmental effects for the remaining $18 \%$.

Partner educational attainment level had no significant effect on the means in the young cohort, but did have a significant effect on the means in the older cohort, which was equal for males and females (Model 4 vs Model 3: $\left.\chi^{2}(3)=1.25, n s\right)$. These findings suggest a cohort-effect: FSIQ scores of older subjects whose partners were more

Table 3 Model fitting results for an interaction model of full scale IQ with partner educational attainment level as moderator

\begin{tabular}{|c|c|c|c|c|c|c|}
\hline & Partner educ & $-2 \mathrm{LL}$ & Df & $\chi_{\text {diff }}^{2}$ & $\mathrm{Df}_{\text {diff }}$ & $P$ \\
\hline \multirow[t]{4}{*}{ Model 1} & Full model & 5578.779 & 723 & & & \\
\hline & Equalize unmoderated parts of variance ( $\mathrm{a}, \mathrm{c}$, an e) across sex and cohort & 5591.781 & 732 & 13.002 & 9 & 0.16 \\
\hline & Equalize unmoderated part means (m) across sex and cohort & 5597.746 & 735 & 5.965 & 3 & 0.11 \\
\hline & Drop parameter c & 5597.998 & 736 & 0.25 & 1 & 0.62 \\
\hline Model 2 & Equalize moderation parameters $\mathrm{a}^{\prime}, \mathrm{c}^{\prime}$ and $\mathrm{e}^{\prime}$ (variances) across sex and cohort & 5601.423 & 745 & 3.435 & 9 & 0.94 \\
\hline Model 3 & Drop all moderation on the variances & 5605.035 & 748 & 3.612 & 3 & 0.31 \\
\hline Model 4 & Drop moderation on means $\left(\mathrm{m}^{\prime}\right)$ for young cohort, equalize for old cohort & 5606.282 & 751 & 1.247 & 3 & 0.74 \\
\hline \multicolumn{7}{|c|}{ Parameters final model } \\
\hline \multirow[t]{2}{*}{ Means } & $\mathrm{m}=103.6656$ & & Variances & $\mathrm{A}=10.31$ & & \\
\hline & $\mathrm{m}_{\mathrm{o}}^{\prime}=2.23$ & & & $\mathrm{E}=4.87$ & & \\
\hline
\end{tabular}

Note: Parameters a, c and e refer to the unmoderated parts of the variance components A (additive genetic effects), C (common environmental effects) and E (unique environmental effects) of FSIQ, while parameters $a^{\prime}, c^{\prime}$ and $e^{\prime}$ refer to the moderation parameters of these variance components. Parameter $\mathrm{m}$ refers to the unmoderated part of the means model, while parameter $\mathrm{m}^{\prime}$ refers to the moderation effect in the means. Subscripts refer to young (y) or old (o) and males (m) or females (f), respectively 
Table 4 Model fitting results for an interaction model of full scale IQ with urbanization level as moderator

\begin{tabular}{|c|c|c|c|c|c|c|}
\hline & Urbanization & $-2 \mathrm{LL}$ & Df & $\chi_{\text {diff }}^{2}$ & $\mathrm{Df}_{\text {diff }}$ & $P$ \\
\hline Model 1 & Full model & 5593.224 & 723 & & & \\
\hline $1 \mathrm{a}$ & Equalize unmoderated parts of variance ( $\mathrm{a}, \mathrm{c}$, an e) across sex and cohort & 5603.054 & 732 & 9.83 & 9 & 0.36 \\
\hline $1 \mathrm{~b}$ & Equalize unmoderated part means (m) across sex and cohort & 5604.026 & 735 & 0.972 & 3 & 0.81 \\
\hline $1 \mathrm{c}$ & Drop parameter c & 5604.487 & 736 & 0.461 & 1 & 0.50 \\
\hline Model 2 & Equalize moderation parameters $\mathrm{a}^{\prime}, \mathrm{c}^{\prime}$ and $\mathrm{e}^{\prime}$ (variances) across sex and cohort & 5615.436 & 745 & 10.949 & 9 & 0.28 \\
\hline Model 3 & Drop all moderation on the variances & 5616.621 & 748 & 1.185 & 3 & 0.76 \\
\hline Model 4 & Equalize moderation parameter means $\left(\mathrm{m}^{\prime}\right)$ across sex and cohort & 5621.146 & 751 & 4.525 & 3 & 0.21 \\
\hline Model 5 & Drop moderation means & 5621.951 & 752 & 0.805 & 1 & 0.37 \\
\hline Model 6 & Drop moderation means, but not in young males & 5618.461 & 751 & 3.49 & 1 & 0.06 \\
\hline \multicolumn{7}{|c|}{ Parameters final model } \\
\hline Means & $\begin{array}{l}\mathrm{M}=103.76 \\
\mathrm{~m}_{\mathrm{ym}}^{\prime}=-0.80\end{array}$ & & Variances & $\begin{array}{l}A=10.48 \\
E=4.86\end{array}$ & & \\
\hline
\end{tabular}

Note: Parameters a, c and e refer to the unmoderated parts of the variance components A (additive genetic effects), C (common environmental effects) and $\mathrm{E}$ (unique environmental effects) of FSIQ, while parameters $\mathrm{a}^{\prime}, \mathrm{c}^{\prime}$ and $\mathrm{e}^{\prime}$ refer to the moderation parameters of these variance components. Parameter $\mathrm{m}$ refers to the unmoderated part of the means model, while parameter $\mathrm{m}^{\prime}$ refers to the moderation effect in the means. Subscripts refer to young (y) or old (o) and males (m) or females (f), respectively

highly educated were on average a full 2 IQ points higher, compared to the FSIQ scores of older subjects whose partners were less educated.

\section{Urbanization level of the residential area}

The moderating effects of level of urbanization on the variance components (Table 4) could be set equal across sex and cohort (Model 2 vs Model 1c: $\chi^{2}(9)=10.95, n s$ ), and could be dropped from the model (Model 3 vs Model 2: $\left.\chi^{2}(3)=1.19, n s\right)$. Additive genetic effects accounted for $82 \%$ of the observed variation in FSIQ scores, and unshared environmental effects for the remaining $18 \%$.

The effect of level of urbanization on the means could be constrained to be equal across sex and cohort (Model 4 vs Model 3: $\left.\chi^{2}(3)=4.23, n s\right)$, and dropped from the model (Model 5 vs Model 4: $\chi^{2}(1)<1, n s$ ). A small trend was however observed for younger males, with FSIQ scores being slightly higher (about 0.80 IQ points) in males living in more urbanized areas (Model 6 vs Model 5: $\chi^{2}(1)=$ 3.49, $P=0.06)$. This trend is also visible in Table 1 , where FSIQ scores increase from 99.47 for young males living in areas with very low urbanization, to 106.21 for young males living in areas where urbanization is very high.

\section{Mean real estate price in the residential area}

The moderating effect of mean real estate price of the residential area on the variance components of FSIQ (Table 5) were not significantly different across sex and cohort (Model 2 vs Model 1c: $\chi^{2}(9)=3.78, n s$ ), and could be dropped from the model (Model 3 vs Model 2: $\left.\chi^{2}(3)=5.511, n s\right)$. However, leaving in the moderation parameter for the E-component of older males $\left(\mathrm{e}^{\prime}{ }_{\mathrm{om}}\right) \mathrm{did}$ result in a model with a significantly better fit (Model 3a vs Model 3: $\left.\chi^{2}(1)=5.02, P<0.05\right)$. This parameter was estimated at 0.46 . As mean real estate price was standardized (z-scores), this implies an increase of about $2-3 \%$ of the variance explained by unshared environmental effects with every standard deviation increase in mean real estate price. More precisely, the percentage of variance explained by unshared environmental effects in older males increased from $10 \%$ for subjects with mean real estate price scores more than $3 \mathrm{SD}$ below the average, to $18 \%$ for subjects with an average mean real estate price score, to $26 \%$ for subjects whose mean real estate price score was 3 SD above the mean. As a result, the relative contribution of the additive genetic effects decreases in older males from $90 \%$ via $82 \%$ to $74 \%$, depending on mean real estate price. In the young cohort, and in older females, this moderation was not significant and additive genetic effects and unshared environmental effects accounted for $82 \%$ and $18 \%$ of the variance, respectively, independent of mean real estate price.

The effect of mean real estate price on the mean could be set equal across sex and cohort (Model 4 vs Model 3a: $\left.\chi^{2}(3)=1.28, n s\right)$, and fixing this parameter to zero resulted in a decrease in fit that was close to significant (Model 5 vs Model 4: $\left.\chi^{2}(1)=3.66, P=0.06\right)$. The effect on the means $\left(\mathrm{m}^{\prime}\right)$ was estimated at 0.36 , implying a slight increase in FSIQ scores with every standard deviation increase in mean real estate price.

To investigate the robustness of the effects observed for FSIQ, all analyses were re-run for verbal IQ (VIQ) and performance IQ (PIQ) separately, with VIQ based on the 
Table 5 Model fitting results for an interaction model of full scale IQ with mean real estate price as moderator

\begin{tabular}{|c|c|c|c|c|c|c|}
\hline & Mean real estate price & $-2 \mathrm{LL}$ & Df & $\chi_{\text {diff }}^{2}$ & $\mathrm{Df}_{\text {diff }}$ & $P$ \\
\hline Model 1 & Full model & 5588.163 & 723 & & & \\
\hline $1 \mathrm{a}$ & Equalize unmoderated parts of variance (a, c, an e) across sex and cohort & 5602.742 & 732 & 14.579 & 9 & 0.10 \\
\hline $1 b$ & Equalize unmoderated part means (m) across sex and cohort & 5607.506 & 735 & 4.764 & 3 & 0.19 \\
\hline $1 \mathrm{c}$ & Drop parameter c & 5607.507 & 736 & 0.001 & 1 & 0.97 \\
\hline Model 2 & Equalize moderation parameters $\mathrm{a}^{\prime}, \mathrm{c}^{\prime}$ and $\mathrm{e}^{\prime}$ (variances) across sex and cohort & 5611.287 & 745 & 3.781 & 9 & 0.93 \\
\hline Model 3 & Drop all moderation on the variances & 5616.798 & 748 & 5.511 & 3 & 0.14 \\
\hline Model 3a & Drop all but moderation in $\mathrm{E}$ of older males $\left(\mathrm{e}_{\mathrm{om}}\right)$ & 5611.774 & 747 & 5.024 & 1 & $<0.05$ \\
\hline Model 4 & Equalize moderation parameter means $\left(\mathrm{m}^{\prime}\right)$ across sex and cohort & 5613.055 & 750 & 1.281 & 3 & 0.73 \\
\hline Model 5 & Drop moderation means & 5616.713 & 751 & 3.658 & 1 & 0.06 \\
\hline \multicolumn{7}{|c|}{ Parameters final model } \\
\hline Means & $\begin{array}{l}\mathrm{m}=103.7412 \\
\mathrm{~m}^{\prime}=0.38\end{array}$ & & Variances & $\begin{array}{l}\mathrm{A}=10.4655 \\
\mathrm{E}=4.8456 \\
\mathrm{e}_{\text {om }}^{\prime}=0.4649\end{array}$ & & \\
\hline
\end{tabular}

Note: Parameters a, c and e refer to the unmoderated parts of the variance components A (additive genetic effects), C (common environmental effects) and $\mathrm{E}$ (unique environmental effects) of FSIQ, while parameters $\mathrm{a}^{\prime}, \mathrm{c}^{\prime}$ and $\mathrm{e}^{\prime}$ refer to the moderation parameters of these variance components. Parameter $\mathrm{m}$ refers to the unmoderated part of the means model, while parameter $\mathrm{m}^{\prime}$ refers to the moderation effect in the means. Subscripts refer to young (y) or old (o) and males (m) or females (f), respectively

WAIS subtests Information, Similarities, Vocabulary, Arithmetic and Letter-Number sequencing, and PIQ based on the subtests Block Design, Matrix Reasoning, Picture Completion and Copying.

When VIQ and PIQ were modeled without moderation, the variance could be explained by $\mathrm{A}$ and $\mathrm{E}$ only, and shared environmental effects were insignificant. For VIQ, the $\mathrm{A}$ and $\mathrm{E}$ components could be equated across the four groups, with $78 \%$ of the variance explained by additive genetic effects. For PIQ, A and E were equal in males and females, but not across cohorts. Additive genetic effects explained $68 \%$ of the variance in the young cohort, and $75 \%$ of the variance in the older cohort.

As with FSIQ, parental educational attainment level had significant effects on the means of both VIQ and PIQ, with higher FSIQ scores for participants from more highly educated families (for VIQ, $\mathrm{m}^{\prime}=5.14$; for PIQ, $\left.\mathrm{m}^{\prime}=3.80\right)$. However, in contrast to the results observed for FSIQ, parental education did not significantly moderate the variance of VIQ in older males. A trend for moderation of the variance components of the older males was observed for PIQ, but statistical power was inadequate to detect the actual source of moderation (via A, C or E).

In line with the results for FSIQ, partner educational level had a significant effect on the means of both VIQ and PIQ in the older cohort. Older subjects whose partners were more highly educated had higher VIQ and PIQ scores (for VIQ, $\mathrm{m}^{\prime}{ }_{\mathrm{o}}=2.35$; for PIQ, $\mathrm{m}_{\mathrm{o}}^{\prime}=2.43$ ).

Like with FSIQ, urbanization level influenced the mean VIQ scores of younger males $\left(\mathrm{m}^{\prime}{ }_{\mathrm{ym}}=-1.08\right)$, with lower urbanization levels being associated to lower VIQ scores. This effect however was not replicated for PIQ.
The small means effect of mean real estate price, and the unique environmental variance of older males, as found for FSIQ, were not replicated for PIQ. Similar effects, albeit of smaller size, were however observed for VIQ.

Details on these additional analyses are available online (www.psy.vu.nl/u/s.van.der.sluis).

\section{Discussion}

Previous studies have shown that characteristics of the childhood home-environment can influence the extent to which additive genetic factors and environmental factors contribute to the variability observed in children's cognitive ability. The aim of the present study was to determine whether the variability in cognitive abilities observed in adult subjects is moderated by environmental factors as well. These factors included a characteristic of the childhood home-environment, namely parental educational attainment level, and three largely self-selected characteristics of the adulthood environment, to wit partner educational attainment level, urbanization level of the participant's residential area, and mean real estate price of the participant's residential area. The latter moderator was considered a crude estimate of income.

Contrary to the findings reported in children (e.g., Harden et al. 2007; Turkheimer et al. 2003; Rowe et al. 1999), we did not find any indication of gene by environment interaction in our adult sample, i.e., the variance explained by additive genetic effects in FSIQ, VIQ and PIQ was stable across the levels of all environmental moderators under study. This means that so far, the only two 
studies on moderation in adults' cognitive ability (the present study and the study by Kremen et al. 2005) fail to replicate the differential effects of additive genetic effects in different environments, as has been observed in children. This could suggest that the genes that are vulnerable to environmental influences in childhood, and as such give rise to significant $\mathrm{G} \times \mathrm{E}$ effects, are involved in development of e.g., the brain. Further research is however required to verify this hypothesis.

The small moderation effects that we did observe, were restricted to the older males, and concerned moderation of the environmental variance components $\mathrm{C}$ (parental education) and $\mathrm{E}$ (mean real estate price). In older males, the variance due to unique environmental influences (E) increased with increasing mean real estate price, and the variance due to common environmental influences (C) was larger for higher levels of parental education. This latter result contrasts with the findings reported in the only other study on moderation in adults cognitive ability (Kremen et al. 2005), where common environmental effects were reported to be smaller for higher levels of parental education. Kremen and colleagues, however, studied word recognition ability rather than IQ, which may explain the discrepancy in results.

The present analyses are not informative about the exact mechanism underlying the observed moderation in the environmental variance components $\mathrm{E}$ and $\mathrm{C}$, and at present, it is unknown why this moderation was observed only in the older males in our sample. Speculative explanations may revert to sociological phenomena. For example, with respect to the effect of parental educational attainment level, it is conceivable that expectations and opportunities regarding education, career and intellectual development were considerably different for males and females in the older cohort, and that this difference was smaller in the young cohort. Older males from highly educated parents may have experienced more familial pressure than females of this same generation, or the males and females of the younger generation, resulting in significantly larger shared environmental effects. Such explanations, however, are entirely speculative and further research is required.

Besides the small moderation effects on the variances, significant effects of the moderators on the means were observed in this study. First, higher educational attainment level of the parents was associated with higher FSIQ in their children (about 5 IQ points higher, compared to children whose parents endorsed the lower educational attainment level). This familial association between parents' education and offspring's FSIQ scores is probably due to a combination of shared genetic influences, and vertical cultural transmission, i.e., the transmission of nongenetic information from parent to child (e.g., Fulker 1982,
1993). Second, higher educational attainment level of partners was also associated with higher FSIQ (about 2 IQ points), but only in the older cohort. The Spearman correlation between partner educational level and FSIQ was 0.27 in the old cohort, and only 0.11 in the young cohort. Evidence for assortative mating, i.e., the phenomenon that mate selection is based partly on the phenotype under study, is quite strong for both IQ (e.g., see Jensen 1978 for an overview) and educational level. Our finding that partner educational level is more highly associated to participants' FSIQ scores in the older cohort, is in line with the hypothesis that the degree of assortative mating has decreased over the last few decades (Johnson et al. 1980). It is however also important to note that the partner choice of the subjects from our young cohort may not yet be 'final'. With a mean age of only 26 years in the young cohort, it is conceivable that many of the partners, whose educational attainment levels were reported and analyzed, may not be the final life partners of our subjects. The association between FSIQ and higher educational attainment levels of partners as observed in the older cohort may therefore still take shape in the young cohort when the partner choice is more final. Third, urbanization level had a small main effect on the FSIQ scores of young males, indicating slightly higher FSIQ scores in young males living in more urbanized areas. This effect may be due to the presence of institutes of higher education, and/or the greater employment opportunities in these areas. This effect was however not replicated for PIQ. Fourth, higher mean real estate scores were in the entire sample associated with slightly higher FSIQ scores. All mean effects were replicated for VIQ, and most were replicated for PIQ.

A major limitation of the present study is the relatively small sample size. Because we did not want to rule out possible sex and cohort effects with respect to the moderation, all analyses started out with four groups, i.e., older and younger males and females, which were relatively small considering the complexity of our models. It is therefore conceivable that we missed some small moderation effects actually present in the data due to lack of statistical power. For instance, for the detection of moderation effects of mean real estate price, partner educational attainment and urbanization level on the variance components of FSIQ, the observed power was only 0.48 , 0.36 and 0.11 , respectively. This means that an overall sample size of $N=620, N=950$ and $N=2900$ (where $N$ is the number of subjects for whom both FSIQ and moderator data are available) would actually have been required to obtain a power of $80 \%$. Another limitation concerns the operationalization of our moderators. Mean real estate price is only a proxy of income, and a more exact measure of income is clearly advisable. Similarly, previous studies have shown that the effects of 
urbanization may differ for rich and poor subjects (Dye 2008), but our measure of urbanization did not take into account the affluence of the neighborhood in which our subjects live.

Still, this study contributes to the growing body of evidence (e.g., Button et al. 2005; Jaffee et al. 2003; Johnson and Krueger 2005; Tuvblad et al. 2006) suggesting that the amount of variance attributable to genetic and environmental factors in traits such as cognitive ability, physical health, childhood conduct problems, and antisocial behavior is not static across the entire population, but can vary as a result of environmental moderators related to previous (childhood) or present (adulthood) home-environment.

Acknowledgment Preparation of this manuscript was financially supported by NWO/MaGW VIDI-016-065-318, MH-65322, and DA18673.

Open Access This article is distributed under the terms of the Creative Commons Attribution Noncommercial License which permits any noncommercial use, distribution, and reproduction in any medium, provided the original author(s) and source are credited.

\section{References}

Alarcón M, Plomin R, Fulker DW, Corley R, DeFries JC (1998) Multivariate path analysis of specific cognitive abilities data at 12 years of age in the Colorado Adoption Project. Behav Genet 28:255-264

Asbury K, Wachs TD, Plomin R (2005) Environmental moderators of genetic influence on verbal and nonverbal abilities in early childhood. Intelligence 33:643-661

Bartels M, Rietveld MJH, van Baal GCM, Boomsma DI (2002) Genetic and environmental influences on the development of intelligence. Behav Genet 32(4):237-249

Bergen SE, Gardner CO, Kendler KS (2007) Age-related changes in heritability of behavioral phenotypes over adolescence and young adulthood: a meta-analysis. Twin Res Hum Genet 10(3): 423-433

Boomsma DI, Vink JM, van Beijsterveldt TCEM, de Geus EJC, Beem AL, Mulder EJCM et al (2002) Netherlands twin register: a focus on longitudinal research. Twin Res 5(5):401-406

Boomsma DI, de Geus EJC, Vink JM, Stubbe JH, Distel MA, Hottenga JH et al (2006) Netherlands twin register: from twins to twin families. Twin Res Hum Genet 9(6):849-857

Bouchard TJ Jr, McGue M (1981) Familial studies of intelligence: a review. Science 212:1055-1059

Bratko D (1996) Twin study of verbal and spatial abilities. Pers Individ Diff 21:621-624

Bronfenbrenner U, Ceci SJ (1994) Nature-nurture reconceptualized in developmental perspective: a bioecological model. Psychol Rev 101(4):568-586

Button TMM, Scourfield J, Martin N, Purcell S, McGuffin P (2005) Family dysfunction interacts with genes in the causation of antisocial symptoms. Behav Genet 35(2):115-120

Centraal Bureau voor de Statistiek (2001) Kerncijfers Viercijferige Postal codegebieden 1999 (Indices of four-digit postal code areas 1999). Heerlen, Voorburg, The Netherlands
Devlin B, Daniels M, Roeder K (1997) The heritability of IQ. Nature 388:468-471

Dye C (2008) Health and urban living. Science 319:766-769

Fulker DW (1982) Extensions of the classical twin method. In: BonnTamir B, Cohen T, Goodman RM (eds) Human genetics, part A: the unfolding genome. Alan R. Liss, New York, pp 395-406

Fulker DW (1983) Genetic and cultural transmission in human behavior. In: Weir BS, Eisen EJ, Goodman MM, Namkoong G, Sunderland MA (eds) Proceedings of the second international conference of quantitative genetics. Sinauer, Sunderland, MA, pp 318-340

Gottesman II (1991) Schizophrenia genesis: the origins of madness. Freeman, New York

Harden KP, Turkheimer E, Loehlin JC (2007) Genotype by environment interaction in adolescents' cognitive aptitude. Behav Genet 37:273-283

Jaffee SR, Moffitt TE, Caspi A, Taylor A (2003) Life with (or without) father: the benefits of living with two biological parents depends on the father's antisocial behavior. Child Dev 74(1): $109-126$

Jensen AR (1978) Genetic and behavioral effects of non-random mating. In: Osborne RT, Noble CE, Weyl N (eds) Human variation: the biopsychology of age, race and sex. Academic Press, New York

Johnson W, Krueger RF (2005) Higher perceived life control decreases genetic variance in physical health: evidence from a national twin study. J Pers Soc Psychol 88:165-173

Johnson RC, Ahern FM, Cole RE (1980) Secular change in the degree of assortative mating for ability? Behav Genet 10:1-8

Kremen WS, Jacobson KC, Xian H, Eisen SA, Waterman B, Toomey R, Neale MC, Tsuang MT, Lyons MJ (2005) Heritability of word recognition in middle-aged men varies as a function of parental education. Behav Genet 35(4):417-433

Luciano M, Wright M, Smith GA, Geffen GM, Geffen LB, Martin NG (2001) Genetic covariance among measures of information processing speed, working memory, and IQ. Behav Genet 31(6): $581-592$

McCartney K, Harris MJ, Bernieri F (1990) Growing up and growing apart: a developmental meta-analysis of twin studies. Psychol Bull 107:226-237

McGue M, Bouchard TJ, Iacono WG, Lykken DT (1993) Behavioral genetics of cognitive ability: a life-span perspective. In: Plomin R, McClearn GE (eds) Nature, nurture and psychology. American Psychology Association, Washington, DC, pp 59-76

Nagoshi CT, Johnson RC (2005) Socioeconomic status does not moderate the familiarity of cognitive abilities in the Hawaii family study of cognition. J Biosoc Sci 37(6):773-781

Paris J (1999) Genetics and psychopathology: predisposition-stress interactions. American Psychiatric Press, Washington, DC

Pedersen CB, Mortensen PB (2001) Evidence of a dose-response relationship between urbanicity during upbringing and schizophrenia risk. Arch Gen Psychiatry 58:1039-1046

Peen J, Dekker J (2003) Urbanization as a risk factor for psychiatric admission. Soc Psychiatry Psychiatr Epidemiol 38:535-538

Plomin R, Rutter M (1998) Child development, molecular genetics, and what to do with genes once they are found. Child Dev 69(4): $1223-1242$

Plomin R, Fulker DW, Corley R, DeFries JC (1997) Nature, nurture, and cognitive development from 1 to 16 years: a parent-offspring adoption study. Psychol Sci 8:442-447

Plomin R, DeFries JC, McClearn G, McGuffin P (2001) Behavioral genetics, 4th edn. Worth, London

Polderman TJC, Gosso MF, Posthuma D, van Beijsterveldt TCEM, Heutink P, Verhulst FC et al (2006) A longitudinal twin study on IQ, executive functioning, and attention problems during childhood and early adolescence. Acta Neurol Belg 106:191-207 
Posthuma D, De Geus EJ, Bleichrodt N, Boomsma DI (2000) Twinsingleton differences in intelligence? Twin Res 3(2):83-87

Posthuma D, de Geus EJC, Boomsma DI (2001) Perceptual speed and IQ associated through common genetic factors. Behav Genet 31(6):593-602

Posthuma D, Beem AL, de Geus EJ, van Baal GCM, von Hjelmborg JB, Iachine I, Boomsma DI (2003) Theory and practice in quantitative genetics. Twin Res 6:361-376

Purcell S (2002) Variance components models for gene-environment interaction in twin analysis. Twin Res 5(6):554-571

Reynolds CA, Baker LA, Pedersen NL (2000) Multivariate models of mixed assortment: phenotypic assortment and social homogamy for education and fluid ability. Behav Genet 30(6):455-476

Rijsdijk FV, Vernon PA, Boomsma DI (2002) Application of hierarchical genetic models to Raven and WASI subtests: a Dutch twin study. Behav Genet 32(3):199-210

Rowe DC, Jacobson KC, van den Oord EJCG (1999) Genetic and environmental influences on vocabulary IQ: parental education level as moderator. Child Dev 70(5):1151-1162

Schrijvers CTM, Stronks K, van de Mheen H, Mackenbach JP (1999) Explaining educational differences in mortality: the role of behavioral and material factors. Am J Public Health 89:535-40

Stronks K, van de Mheen H, van den Bos J, Mackenbach JP (1997) The interrelationship between income, health and employment status. Int J Epidemiol 26:592-600

Sundquist K, Frank G (2004) Urbanization and hospital admission rates for alcohol and drug abuse: a follow-up study of 4.5 million women and men in Sweden. Addiction 99:1298-1305
Sundquist K, Frank G, Sundquist J (2004a) Urbanization and incidence of psychosis and depression: follow-up study of 4.4 million women and men in Sweden. Br J Psychiatry 184:293-298

Sundquist K, Malmstrom M, Johansson SE (2004b) Neighbourhood deprivation and incidence of coronary heart disease: a multilevel study of 2.6 million women and men in Sweden. J Epidemiol Community Health 58:71-77

Turkheimer E, Haley A, Waldron M, D'Onofrio B, Gottesman II (2003) Socioeconomic status modifies heritability of IQ in young children. Psychol Sci 14(6):623-628

Tuvblad C, Grann M, Lichtenstein P (2006) Heritability for adolescent antisocial behavior differs with socioeconomic status: geneenvironment interaction. J Child Psychol Psychiatry 47(7): 734-743

Van den Oord EJCG, Rowe DC (1997) An examination of genotypeenvironment interactions for academic achievement in an U.S. national longitudinal survey. Intelligence 25(3):205-228

WAIS-III (1997) Dutch version. Manual. Lisse. Swets and Zeitlinger.

Willemsen G, Posthuma D, Boomsma DI (2005) Environmental factors determine where the Dutch live: results from the Netherlands Twin Register. Twin Res Hum Genet 8(4): 312-317

Wright M, de Geus EJN, Ando J, Luciano M, Posthuma D, Ono Y et al (2001) Genetics of cognition: outline of a collaborative twin study. Twin Res 4(1):48-56 